\title{
ERRATUM
}

Niraldo Paulino $\cdot$ Moacir G. Pizollatti

Rosendo A. Yunes - Valdir Cechinel Filho

Tania B. Creczynski-Pasa $\cdot$ João B. Calixto

\section{The mechanisms underlying the relaxant effect of methyl and ethyl gallates in the guinea pig trachea in vitro: contribution of potassium channels}

Published online: 10 September 1999

Naunyn-Schmiedeberg's Arch Pharmacol (1999) 360:331-336

The name of the co-author Valdir Cechinel Filho was accidentally omitted from the original manuscript.

The online version of the original article can be found at http://dx.doi.org/10.1007/s002109900081

T. B. Creczynski-Pasa $\cdot$ J. B. Calixto $(\Xi)$

Department of Pharmacology, Centre of Biological Sciences,

Universidade Federal de Santa Catarina, Rua Ferreira Lima, 82,

88015-420 Florianópolis, SC, Brazil

e-mail: calixto@farmaco.ufsc.br,

Fax: +55-482-224164

M. G. Pizollatti · R. A. Yunes · V. C. Filho

Department of Chemistry,

Universidade Federal de Santa Catarina,

88049-900 Florianópolis, SC, Brazil

N. Paulino

College of Pharmacy, Universidade do Sul de Santa Catarina,

88704-900 Tubarão, SC, Brazi 